\title{
Superacid-Induced Reactions of Nefopam
}

\author{
Larecia Knoecer, Daniel DeSchepper, and Douglas A. Klumpp \\ Department of Chemistry and Biochemistry, Northern Illinois University, DeKalb, IL 60115, USA \\ Correspondence should be addressed to Douglas A. Klumpp, dklumpp@niu.edu
}

Received 10 November 2009; Revised 13 February 2010; Accepted 16 March 2010

Academic Editor: Cyril Parkanyi

Copyright ( 2010 Larecia Knoecer et al. This is an open access article distributed under the Creative Commons Attribution License, which permits unrestricted use, distribution, and reproduction in any medium, provided the original work is properly cited.

The analgesic drug nefopam reacts in superacidic media to form a dicationic superelectrophiles by ring opening. The dication species is capable of reacting with arenes in Friedel-Crafts-type conversions. This chemistry is used to prepare novel derivatives of nefopam.

During the 1970s, Olah and coworkers proposed the concept of superlectrophilic activation [1]. Those seminal reports prompted many subsequent investigations of dicationic electrophilic species and superelectrophiles [2]. Superelectrophiles may arise from the interaction of cationic electrophiles with acidic media, as in the protonation of the nitronium cation $[3,4]$. In the limiting case, dicationic superelectrophiles may be produced. Due to the increased positive charge, superelectrophiles are often reactive towards very weak nucleophiles (i.e., alkanes and deactivated arenes) [2]. A number of studies have also demonstrated that highly reactive, dicationic electrophiles may involve ionization of strong base sites adjacent to electrophilic centers [5]. For example, 4-pyridinecarboxaldehyde forms the superelectrophile in $\mathrm{CF}_{3} \mathrm{SO}_{3} \mathrm{H}$ by protonation of the pyridine ring and the carbonyl group [6]. The resulting dication is capable of reacting with saturated hydrocarbons or nitrobenzene [6].

Recently, we reported the ionization of aminoalcohols in superacid to give highly reactive dicationic electrophiles [7]. Similarly, ionizations of amino acetals, amino olefins, and amino alkynes were shown to give reactive superelectrophiles [8-10]. Prompted by these earlier studies, we have sought to identify other substrates capable of forming superelectrophiles in strongly acidic media. In the following letter, we report our studies of the acid-catalyzed ring-opening reactions of 5-methyl-1-phenyl-3,4,5,6-tetrahydro-1H-benzo[ $f$ ] $[1,5]$ oxazocine (nefopam, a common analgesic drug) and the preparation of novel derivatives of this compound.
The degradation of nefopam (1) under stressed storage conditions $\left(90^{\circ} \mathrm{C}\right.$ in alkaline, $\mathrm{pH}$ 9.0, and acidic, $\mathrm{pH} 2.0$, media) was studied by Wang and coworkers [11]. Among their observations, it was reported that the acidic conditions promoted ether cleavage to the diol (4, Scheme 1) along with other products. They proposed a mechanism shown in Scheme 1, involving formations of dications 2 and 3. Although dication 3 has a resonance stabilized carbocationic center, we reasoned that it should have relatively high elecrophilic reactivity due to its dicationic, superelectrophilic structure.

When nefopam (1) was reacted with several types of arenes in $\mathrm{CF}_{3} \mathrm{SO}_{3} \mathrm{H}$, the products from electrophilic aromatic substitution were obtained in fair to good yield (Table 1).

Analytical data for new compounds: 5: $\mathrm{mp} 115-118^{\circ} \mathrm{C}$; ${ }^{1} \mathrm{H} \mathrm{NMR}\left(500 \mathrm{MHz}, \mathrm{CDCl}_{3}\right), 2.22(\mathrm{~s}, 3 \mathrm{H}), 2.56(\mathrm{t}, J=9.0 \mathrm{~Hz}$, $2 \mathrm{H}), 3.53(\mathrm{~s}, 2 \mathrm{H}), 3.59(\mathrm{t}, J=9.0 \mathrm{~Hz}, 2 \mathrm{H}), 6.12(\mathrm{~s}, 1 \mathrm{H})$, 6.92-6.96 (m, 1H), 7.04-7.07 (m, 4H), 7.19-7.31 (m, 9H); ${ }^{13} \mathrm{C}$ NMR $\left(125 \mathrm{MHz}, \mathrm{CDCl}_{3}\right), 41.7,52.1,58.7,59.0,60.9$, $126.5,126.6,127.8,128.6,129.7,1129.9,130.7,131.2,143.5$, 143.8; MS (EI), $331(\mathrm{M}+), 300,256,179,178$. 6: Clear oil, ${ }^{1} \mathrm{H}$ NMR $\left(500 \mathrm{MHz}, \mathrm{CDCl}_{3}\right), 2.21(\mathrm{~s}, 3 \mathrm{H}), 2.22(\mathrm{~s}, 3 \mathrm{H}), 2.26$ $(\mathrm{s}, 3 \mathrm{H}), 2.58(\mathrm{t}, J=5.3 \mathrm{~Hz}, 2 \mathrm{H}), 3.45-3.53(\mathrm{~m}, 2 \mathrm{H}), 3.60(\mathrm{t}$, $J=5.2 \mathrm{~Hz}, 2 \mathrm{H}), 6.08(\mathrm{~s}, 1 \mathrm{H}), 6.78(\mathrm{~d}, J=7.6 \mathrm{~Hz}, 1 \mathrm{H}), 6.86$ (s, 1H), 6.96-6.97 (m, 1H), 7.05-7.08 (m, 3H), 7.20-7.23 (m, $3 \mathrm{H}), 7.28-7.30(\mathrm{~m}, 3 \mathrm{H}) ;{ }^{13} \mathrm{C}$ NMR $\left(125 \mathrm{MHz}, \mathrm{CDCl}_{3}\right), 19.4$, $19.9,41.5,51.5,58.7,58.8,60.9,126.1,126.9,127.4,128.3$, $129.5,129.5,130.4,130.8,130.9,134.3,134.4,136.4,141.1$, 
<smiles>CN1CCOC(c2ccccc2)c2ccccc2C1</smiles>

1

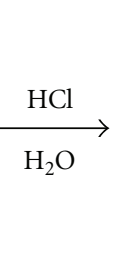

(1)

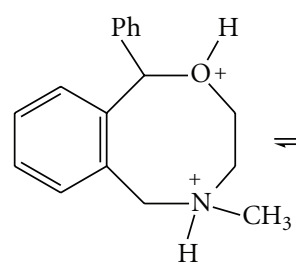

2

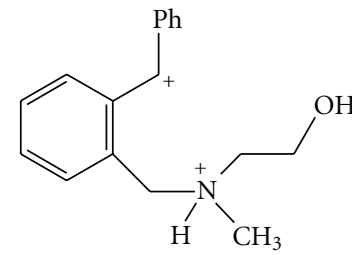

3

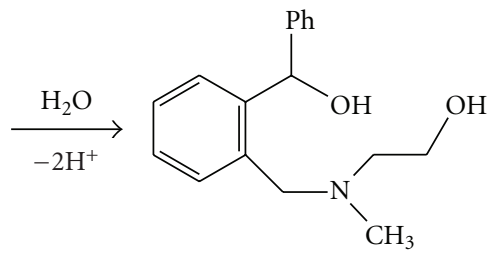

4

Scheme 1

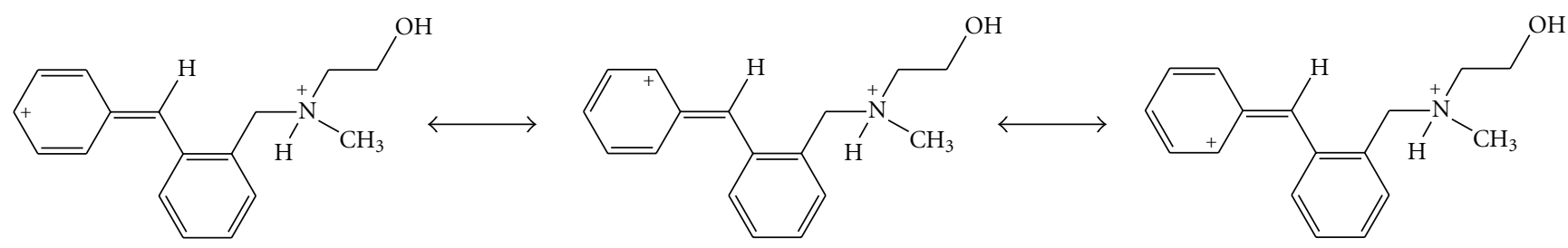

SCHEMe 2

141.2, 143.5, 144.0; MS (EI), 359 (M+), 269, 207, 178, 91. 7: $\mathrm{mp} 101-105^{\circ} \mathrm{C} ;{ }^{1} \mathrm{H}$ NMR $\left(500 \mathrm{MHz}, \mathrm{CDCl}_{3}\right) 2.23$ (s, 3H), $2.59(\mathrm{t}, J=5.3 \mathrm{~Hz}, 2 \mathrm{H}), 3.47(\mathrm{~d}, J=12.9 \mathrm{~Hz}, 1 \mathrm{H}), 3.52(\mathrm{~d}$, $J=12.9 \mathrm{~Hz}, 1 \mathrm{H}), 3.61(\mathrm{t}, J=5.3 \mathrm{~Hz}, 2 \mathrm{H}), 3.77(\mathrm{~s}, 3 \mathrm{H}), 3.87$ (s, 3H), 6.14 (s, 1H), 6.55-6.56 (m, 1H), $6.67(\mathrm{~s}, 1 \mathrm{H}), 6.80(\mathrm{~d}$, $J=8.2 \mathrm{~Hz}, 1 \mathrm{H}), 6.95-6.97(\mathrm{~m}, 1 \mathrm{H}), 7.09(\mathrm{~d}, J=7.6 \mathrm{~Hz}, 1 \mathrm{H})$, 7.21-7.25 (m, 3H), 7.28-7.32 (m, 3H); ${ }^{13} \mathrm{C} \mathrm{NMR} \mathrm{(125} \mathrm{MHz,}$ $\left.\mathrm{CDCl}_{3}\right)$ 41.7, 51.4, 55.8, 55.8, 58.7, 58.9, 60.9, 110.9,112.9, $121.5,126.3,126.3,127.4,128.3,129.4,130.3,130.9,136.3$, 136.5, 143.6, 143.9, 147.4, 148.9; MS (EI), 391 (M+), 316, 285, 239, 178. 8: Clear oil, ${ }^{1} \mathrm{H}$ NMR (500 MHz, $\left.\mathrm{CDCl}_{3}\right) 2.21$ $(\mathrm{s}, 3 \mathrm{H}), 2.56(\mathrm{t}, J=5.1 \mathrm{~Hz}, 2 \mathrm{H}), 3.45-3.51(\mathrm{~m}, 2 \mathrm{H}), 3.59(\mathrm{t}$, $J=5.2 \mathrm{~Hz}, 2 \mathrm{H}), 3.79-3.80(\mathrm{~m}, 4 \mathrm{H}), 4.08(\mathrm{t}, J=3.4 \mathrm{~Hz}, 2 \mathrm{H})$, 4.16-4.20 (m, 2H), 6.11 (s, 1H), 6.61-6.63 (m, 1H), $6.71(\mathrm{~s}$, $1 \mathrm{H}), 6.88(\mathrm{~d}, J=8.2 \mathrm{~Hz}, 1 \mathrm{H}), 6.92-6.94(\mathrm{~m}, 1 \mathrm{H}), 7.07(\mathrm{~d}$, $J=7.4 \mathrm{~Hz}, 2 \mathrm{H}), 7.19-7.22(\mathrm{~m}, 3 \mathrm{H}), 7.26-7.28(\mathrm{~m}, 3 \mathrm{H}) ;{ }^{13} \mathrm{C}$ NMR (125 MHz, $\mathrm{CDCl}_{3}$ ) 41.7, 51.3, 58.8, 59.0, 60.8, 69.9, $70.0,71.2,71.6,72.0,117.9,119.3,123.5,126.3,126.3,127.4$, $128.3,129.5,130.3,130.9,136.3,138.3,143.4,143.8,149.0$, 150.5. MS (EI): 477 (M+), 459, 297, 237, 179. 9: clear oil, ${ }^{1} \mathrm{H} \mathrm{NMR}\left(500 \mathrm{MHz}, \mathrm{CDCl}_{3}\right) 2.36(\mathrm{~s}, 3 \mathrm{H}), 2.66(\mathrm{t}, J=5.0 \mathrm{~Hz}$, $2 \mathrm{H}), 3.68(\mathrm{t}, J=5.2 \mathrm{~Hz}, 2 \mathrm{H}), 3.71(\mathrm{~s}, 2 \mathrm{H}), 6.25(\mathrm{~s}, 1 \mathrm{H}), 6.78-$ $6.80(\mathrm{~m}, 2 \mathrm{H}), 7.01(\mathrm{~d}, J=7.1 \mathrm{~Hz}, 2 \mathrm{H}), 7.15-7.33(\mathrm{~m}, 6 \mathrm{H})$, $7.44(\mathrm{~m}, 2 \mathrm{H}) .{ }^{13} \mathrm{C}$ NMR $\left(125 \mathrm{MHz}, \mathrm{CDCl}_{3}\right) 41.5,49.2,57.9$, 58.8, 59.7, 127.1, 127.3, 128.3, 128.8, 129.4, 129.6, 129.7, $131.1,132.2,133.2,134.9,139.7,141.2,141.4$; MS (EI): 401, $399(\mathrm{M}+), 370,368,2112,179$.

In a typical procedure, $0.2 \mathrm{~g}$ of nefopam hydrochloride salt is suspended in benzene $(1.0 \mathrm{~mL})$ and $\mathrm{CF}_{3} \mathrm{SO}_{3} \mathrm{H}(3.0 \mathrm{~mL})$ is slowly added (caution: $\mathrm{HCl}$ gas is released). The mixture is stirred for 12 hours, and then poured over ice and made basic by dropwise addition of $10 \mathrm{M} \mathrm{NaOH}$. The product is extracted into $\mathrm{CHCl}_{3}$ and the organic layer is washed by water and then brine. The resulting solution is dried with $\mathrm{MgSO}_{4}$, filter, and concentrated to give product 13, which can be further purified by column chromatography (silica, hexane:ether). In the case of product $\mathbf{8}$, the reaction is best done using $0.1 \mathrm{mmol}$ nefopam $\mathrm{HCl}, 0.1 \mathrm{mmol}$ benzo-12crown-4, $3 \mathrm{~mL} \mathrm{CHCl}$, and $0.5 \mathrm{~mL} \mathrm{CF} \mathrm{SO}_{3} \mathrm{H}$. The reaction is initially stirred at $0^{\circ} \mathrm{C}$, and then allowed to stir at room temperature.

In the reaction with benzene, the conversion is found to be complete within 30 minutes at $25^{\circ} \mathrm{C}$ with 60 equivalents of $\mathrm{CF}_{3} \mathrm{SO}_{3} \mathrm{H}$, but it will also proceed to completion with as little as 3 equivalents of $\mathrm{CF}_{3} \mathrm{SO}_{3} \mathrm{H}$. Product 5 is not obtained in useful yields from reactions catalyzed by $\mathrm{H}_{2} \mathrm{SO}_{4}$ or $\mathrm{CF}_{3} \mathrm{CO}_{2} \mathrm{H}$. In the case of $\mathrm{H}_{2} \mathrm{SO}_{4}$, the nefopam is consumed, however the products are water soluble and could not be identified. With $\mathrm{CF}_{3} \mathrm{CO}_{2} \mathrm{H}$, unreacted nefopam is recovered. Other arenes found to react with nefopam in $\mathrm{CF}_{3} \mathrm{SO}_{3} \mathrm{H}$, include: $o$-xylene, 1, 2-dimethoxybenzene, benzo-12-crown4 , and $m$-dichlorobenzene. These arenes give the respective substitution products (6-9). In general, the arylation of nefopam works best with electron-rich arenes. Some arenes, however, were found to be unsuitable for the reaction conditions due to decomposition (i.e., thiophene, indole, 1,3-benzodioxole). Despite the low yield of product 9, the conversion with $m$-dichlorobenzene is notable because this arene is somewhat deactivated due to the chloro substituents. Formation of product 9 indicates a fairly high level of electrophilic reactivity for the superelectrophile 3 .

In order to gain further evidence for the involvement of the ring-opened superelectrophile (3), NMR experiments were done. NMR samples were prepared by dissolving nefopam in acids having widely varying strengths: $\mathrm{CF}_{3} \mathrm{CO}_{2} \mathrm{H}$ $\left(H_{o}-2.7\right), \mathrm{FSO}_{3} \mathrm{H}\left(H_{o}-15.1\right), \mathrm{FSO}_{3} \mathrm{H}_{-}-\mathrm{SbF}_{5}\left(H_{o}-20\right)$. Under stable ion conditions $[12,13]$ (superacidic solution and low temperature), evidence for the carbocationic superelectrophile (3) is obtained. With superacidic solution $\left(\mathrm{FSO}_{3} \mathrm{H}-\right.$ $\mathrm{SO}_{2} \mathrm{ClF}$ or $\mathrm{FSO}_{3} \mathrm{H}-\mathrm{SbF}_{5}-\mathrm{SO}_{2} \mathrm{ClF}$ ), the ${ }^{13} \mathrm{C} \mathrm{NMR}$ spectra of the nefopam product shows down field resonances around $\delta$ 192, a value close to other diarylalkyl carbocations [7, 14]. However even at $-50^{\circ} \mathrm{C}$, the ${ }^{13} \mathrm{C}$ NMR spectra are unexpectedly complex. Whereas superelectrophile 3 should 
TABLE 1: Products and isolated yields from the reactions of nefopam 1 with nucleophiles in $\mathrm{CF}_{3} \mathrm{SO}_{3} \mathrm{H}_{\text {or }} \mathrm{CF}_{3} \mathrm{CO}_{2} \mathrm{H}$.

\begin{tabular}{|c|c|c|c|}
\hline Entry & Nucleophile & Product & Isolated Yield \\
\hline 1 & Benzene & & $94 \%$ \\
\hline 2 & $o$-Xylene & 6 & $80 \%$ \\
\hline 3 & 1,2-Dimethoxy-benzene & 7 & $81 \%$ \\
\hline 4 & Benzo-12-crown-4 & 8 & $93 \%$ \\
\hline 5 & 1,3-Dichloro-benzene & 9 & $22 \%$ \\
\hline
\end{tabular}




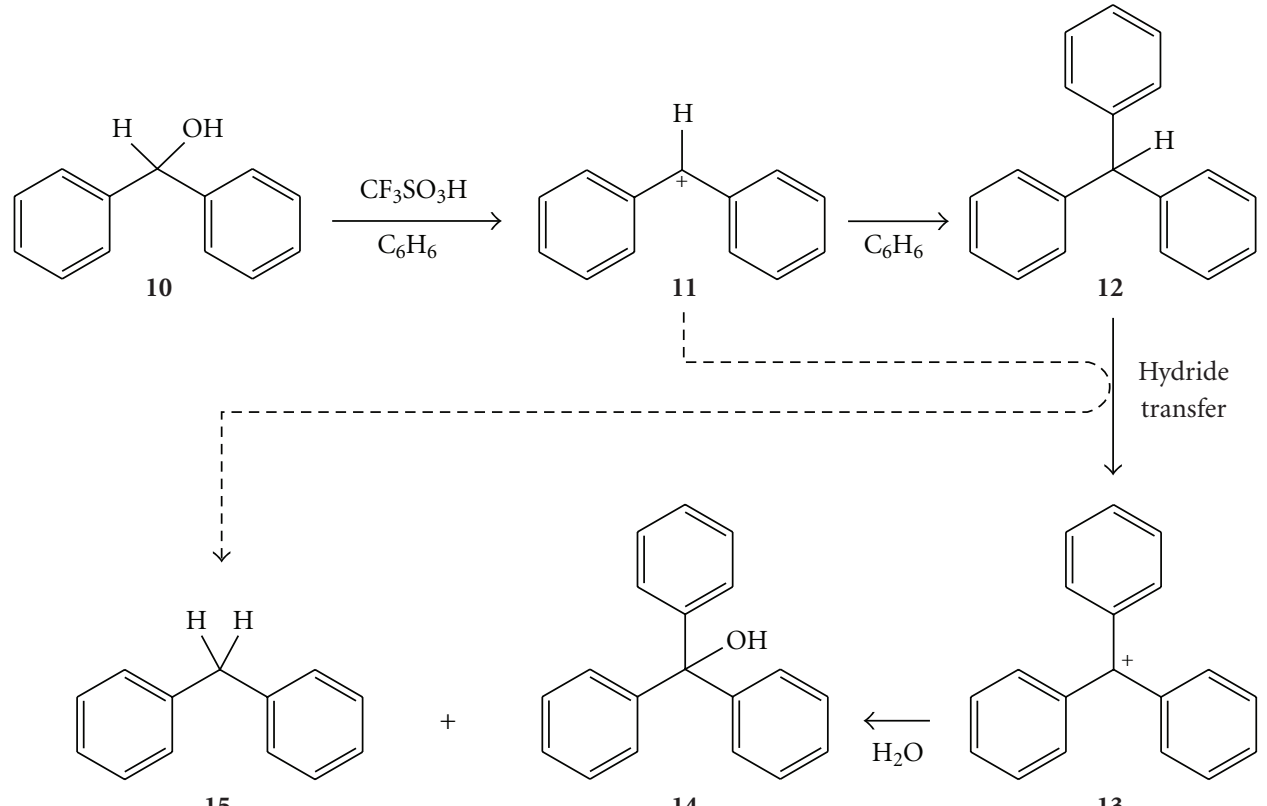

Scheme 3<smiles>C[N+](CCO)(Cc1ccccc1C=Cc1ccccc1)Cc1ccccc1C(c1ccccc1)c1ccccc1</smiles><smiles>CN(CCO)Cc1ccccc1C(O)(c1ccccc1)c1ccccc1Cc1ccccc1</smiles>

SCHEMe 4

give $15{ }^{13} \mathrm{C}$ signals, there are around 30 signals in $\mathrm{FSO}_{3} \mathrm{H}$ $\mathrm{SO}_{2} \mathrm{ClF}$ solution and around 18 well-resolved signals in $\mathrm{FSO}_{3} \mathrm{H}-\mathrm{SbF}_{5}-\mathrm{SO}_{2} \mathrm{ClF}$ solution. These complex ${ }^{13} \mathrm{C}$ NMR spectra may be the result of equilibria with the ringclosed species (2) or other products. The spectra may also be complicated by restricted rotation due to charge delocalization (Scheme 2). In $\mathrm{CF}_{3} \mathrm{CO}_{2} \mathrm{H}\left(-10^{\circ} \mathrm{C}\right)$, a very complex ${ }^{13} \mathrm{C}$ NMR spectrum is obtained which has roughly 50 resonance signals arising from nefopam and its ionization products. To an approximation, this suggests an equilibrium between three major components: $\mathrm{N}$-protonated nefopam, the oxonium dication (2), and perhaps a trifluoroacetate adduct. No downfield $(\delta>160)$ resonances were detected, indicating that the free carbocation (3) is not a major component of this equilibrium.
For comparison purposes, diphenylmethanol (10) was also reacted with benzene and triflic acid (Scheme 3 ). We reasoned that diphenylmethanol should ionize cleanly to the monocationic carbocation in superacid and its chemistry would provide a good comparison with the nefopam-derived dicationic intermediate (i.e., 3). When diphenylmethanol is reacted with benzene and triflic acid, two products are observed in approximately equal amounts: diphenylmethane (15) and triphenylmethanol (14, Scheme 3). This suggests formation of the monocation (11), which reacts with benzene to form the intermediate product triphenylmethane (12). The diphenylmethane (15) is generated by hydride transfer between the carbocation $\mathbf{1 1}$ and compound $\mathbf{1 2}$. The observed triphenylmethanol (14) is then formed upon hydrolytic workup of the reaction mixture. 
Interestingly, nefopam does not give analogous products (from hydride transfer reactions) in its conversion with benzene and triflic acid. There may be several factors for the divergent chemistry of nefopam. First, the superelectrophile from nefopam (3) reacts rapidly with benzene, and consequently, the superelectrophile is not formed in appreciable concentration to affect hydride abstraction from the triarylmethane product (15, Scheme 4). Secondly, there is evidence from other superelectrophilic chemistry that charge-charge repulsion can slow intermolecular reactions [2]. Hydride abstraction would require the dicationic elelctrophile 3 to attack the monocation product $\mathbf{1 6}$. However, elelctrostatic effects may preclude this type of intermolecular chemistry.

In summary, nefopam is a common analgesic drug, and the results of this study suggests that it forms a reactive, dicationic superelectrophile in strong and superacidic media. The resulting dicationic intermediate is sufficiently electrophilic to react with nucleophiles such as benzene or 1-3-dichlorobenzene. By exploiting the high reactivity of the ring-opened superelectrophile (3), novel derivatives of nefopam may be prepared. Despite its high electrophilic reactivity, superelelctrophile 3 exhibits cleaner reactions than a closely related monocationic species.

\section{Acknowledgments}

Grateful acknowledgment is made to the National Science Foundation for support of this work (CHE-0749907). The authors also thank Mr. Patrick Kindelin for preliminary studies in this chemistry.

\section{References}

[1] G. A. Olah, A. Germain, H. C. Lin, and D. A. Forsyth, "Electrophilic reactions at single bonds. XVIII. Indication of protosolvated de facto substituting agents in the reactions of alkanes with acetylium and nitronium ions in superacidic media," Journal of the American Chemical Society, vol. 97, no. 10, pp. 2928-2929, 1975.

[2] G. A. Olah and D. A. Klumpp, Superelectrophiles and Their Chemistry, John Wiley \& Sons, New York, NY, USA, 2008.

[3] G. A. Olah, "Superelectrophiles," Angewandte ChemieInternational Edition, vol. 32, no. 6, pp. 767-788, 1993.

[4] G. A. Olah and D. A. Klumpp, "Superelectrophilic solvation," Accounts of Chemical Research, vol. 37, no. 4, pp. 211-220, 2004.

[5] D. A. Klumpp, "Activation of electrophilic sites by adjacent cationic groups," in Recent Developments in Carbocation and Onium Ion Chemistry, K. Laali, Ed., vol. 965 of ACS Symposium Series, chapter 8, pp. 144-159, American Chemical Society, Washington, DC, USA, 2007.

[6] D. A. Klumpp, Y. Zhang, P. J. Kindelin, and S. Lau, "Superacidcatalyzed reactions of pyridinecarboxaldehydes," Tetrahedron, vol. 62, no. 25, pp. 5915-5921, 2006.

[7] D. A. Klumpp, S. L. Aguirre, G. V. Sanchez Jr., and S. J. de Leon, "Reactions of amino alcohols in superacid: the direct observation of dicationic intermediates and their application in synthesis," Organic Letters, vol. 3, no. 17, pp. 2781-2784, 2001.
[8] D. A. Klumpp, G. V. Sanchez Jr., S. L. Aguirre, Y. Zhang, and S. de Leon, "Chemistry of dicationic electrophiles: superacidcatalyzed reactions of amino acetals," Journal of Organic Chemistry, vol. 67, no. 14, pp. 5028-5031, 2002.

[9] Y. Zhang, A. McElrea, G. V. Sanchez Jr., et al., "Dicationic electrophiles from olefinic amines in superacid," Journal of Organic Chemistry, vol. 68, no. 13, pp. 5119-5122, 2003.

[10] D. A. Klumpp, R. Rendy, Y. Zhang, A. McElrea, A. Gomez, and H. Dang, "Reactive dications: the superacid-catalyzed reactions of alkynes bearing adjacent $\mathrm{N}$-heterocycles or amine groups," Journal of Organic Chemistry, vol. 69, no. 23, pp. 8108-8110, 2004.

[11] D.-P. Wang, Y.-H. Tu, L. V. Allen Jr., and F.-C. Cheng, "Degradation mechanism of nefopam in solution under stressed storage conditions," Acta Pharmaceutica Nordica, vol. 2, no. 2, pp. 73-82, 1990.

[12] G. K. S. Prakash, "Electrophilic intermediates and their reactions in superacids," Journal of Organic Chemistry, vol. 71, no. 10, pp. 3661-3676, 2006.

[13] G. K. S. Prakash, "Investigations on intriguing long lived carbodications," Pure and Applied Chemistry, vol. 70, no. 10, pp. 2001-2006, 1998.

[14] G. A. Olah, V. P. Reddy, G. Rasul, and G. K. S. Prakash, "Search for long-lived 1,3-carbodications and preparation of the persistent 1,1,3,3-tetracyclopropyl-1,3-propanediyl dication," Journal of the American Chemical Society, vol. 121, no. 43, pp. 9994-9998, 1999. 


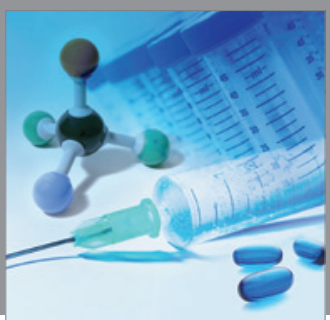

International Journal of

Medicinal Chemistry

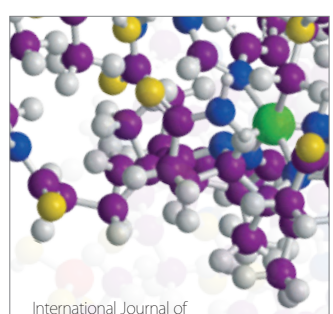

Carbohydrate Chemistry

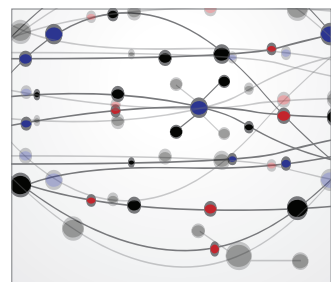

The Scientific World Journal
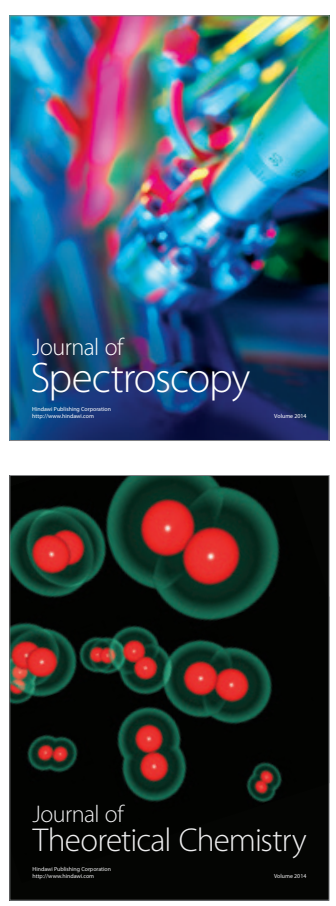
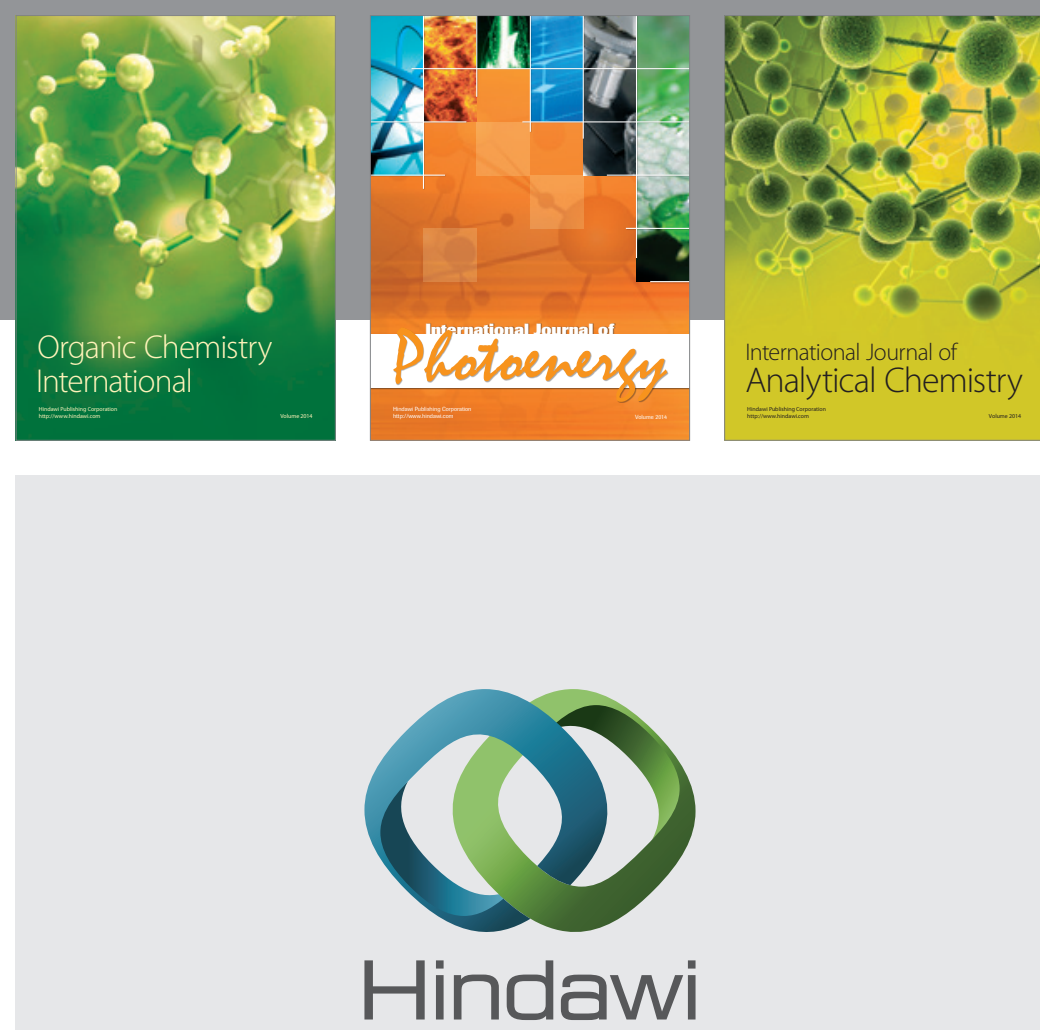

Submit your manuscripts at

http://www.hindawi.com
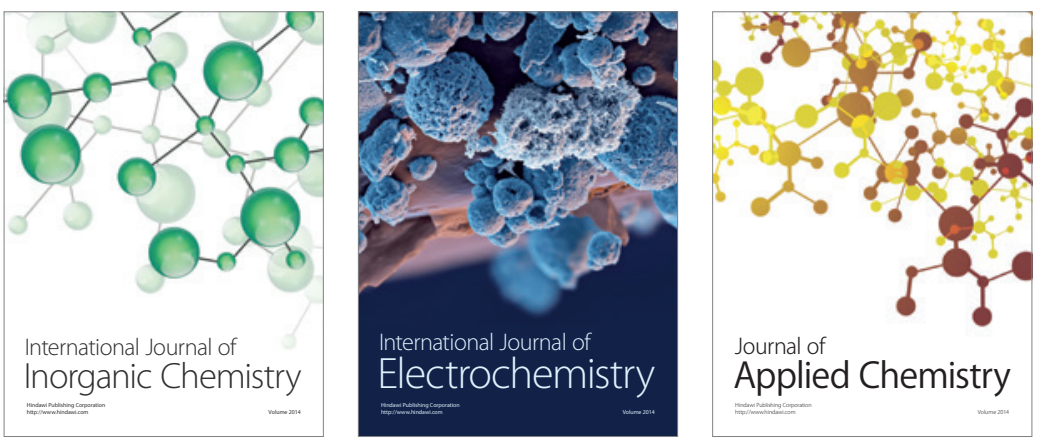

Journal of

Applied Chemistry
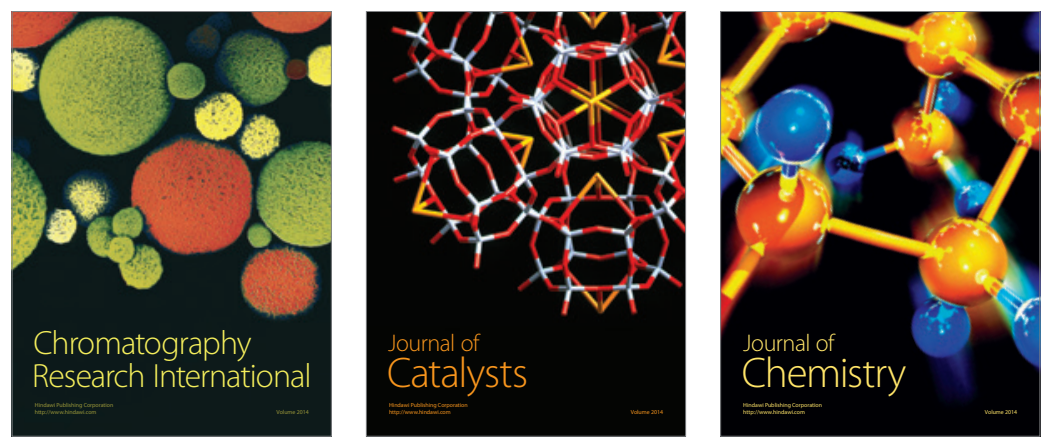
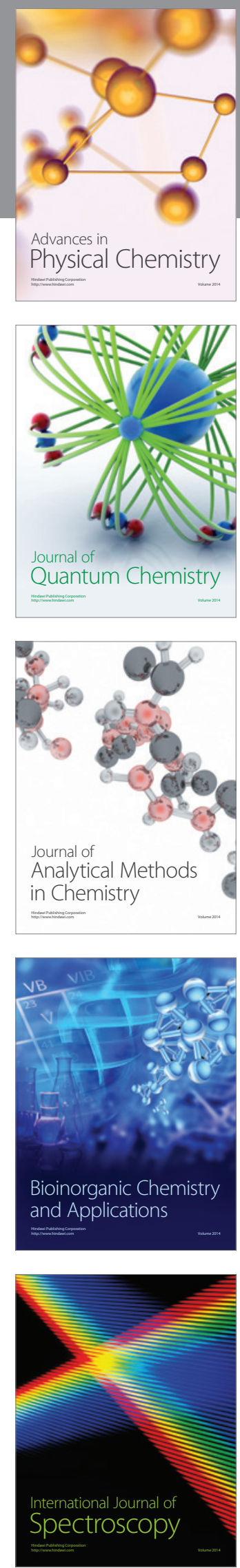